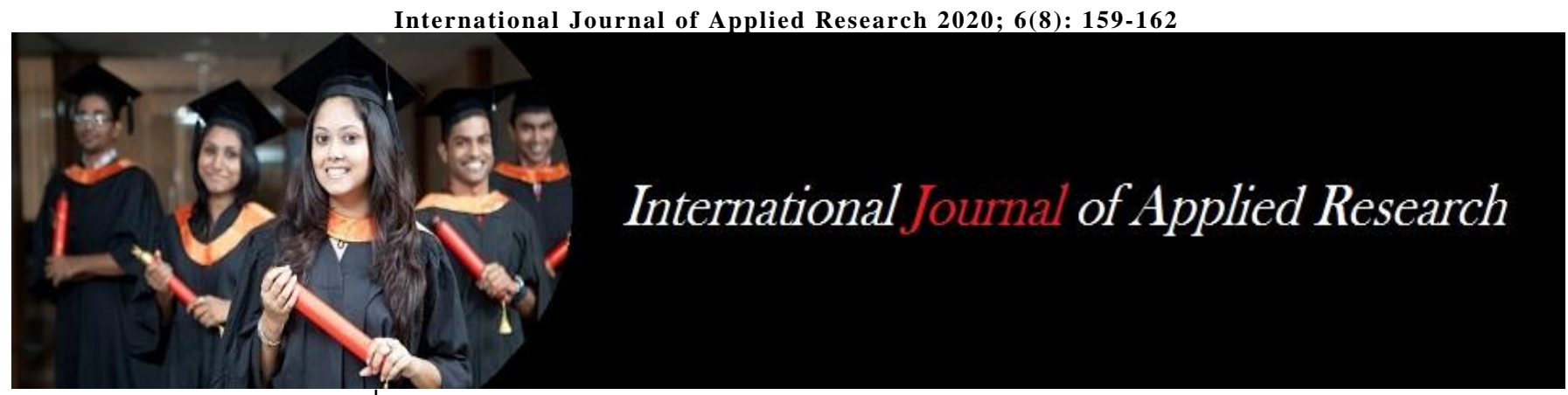

ISSN Print: 2394-7500 ISSN Online: 2394-5869 Impact Factor: 5.2

IJAR 2020; 6(8): 159-162 www.allresearchjournal.com

Received: 02-06-2020 Accepted: 18-07-2020

Muhammad Mubarak

Muhammad

1) Department of

Mathematics, Lovely

Professional University,

Punjab. India

2) Department of Mathematics and Statistics Federal

Polytechnic, Bauchi, Nigeria

Adamu Yusha'u

Department of Mathematics,

Lovely Professional

University, Punjab, India

Ibrahim Y Inuwa

Department of Mathematics

and Statistics Federal

Polytechnic, Bauchi, Nigeria

Mustapha A Usman

Department of Mathematics

and Statistics Federal

Polytechnic, Bauchi, Nigeria

Corresponding Author:

Muhammad Mubarak

Muhammad

1) Department of

Mathematics, Lovely

Professional University,

Punjab. India

2) Department of Mathematics

and Statistics Federal

Polytechnic, Bauchi, Nigeria

\section{Statistical analysis on public evaluation performance of police: A case study of yelwa division}

\author{
Muhammad Mubarak Muhammad, Adamu Yusha'u, Ibrahim Y Inuwa \\ and Mustapha A Usman
}

DOI: https://doi.org/10.22271/allresearch.2020.v6.i8c.6998

\section{Abstract}

This survey was carried out to examine the awareness of people about public evaluation of yelwa police divisional office performance in yelwa police division. Structured questionnaire were administered to both literate and illiterate alike with good response. Chi-square test of independence was employed to analyze the data at $95 \%$ level of significance. It was found out that the efficiency and effectiveness of police authority does not depend on gender and the rate of crime. Based on the findings appropriate recommendation were made.

Keywords: effectiveness, awareness, police performance, evaluation

\section{Introduction}

Under section 194 of the 1979 constitution, the Nigerian police force is designated as the nati onal police with exclusive jurisdiction across the country. The primary function is to protect 1 ife and property, to ensure proper measurement of all functions towards security and crime pr evention, perhaps the most central one is to ensure the safety of citizens with an effective pol ice force. For police to function effectively, they must maintain law and order that require the public's trust and understanding. "Police is your friend then" if we were to live within a world founded on chaos and absolute equality, and if we exist in a society governed by complete control, it would actually be dictatorship. For a long time, people have had poor feelings about the Nigerian police because of the way they deal with issues of urgent concern and even poor relations with the host communities. Identifying these areas and possible suggestions will help to correct these feelings. Nigerian police force's challenges in discharging its functions are both logistic and moral with respect to the government's set level has become increasingly focused on setting goals in an attempt to boost the effectiveness of Nigerian police force. However, there is a lack of consistency to the performance assessment for police work. That requires public confidence and understanding. According to Chiavenato (2005) ${ }^{[1]}$, the notion of performance assessment cannot be considered to be static in its dynamics through a continuous process centered on the person performing any function in a particular organization, with a view to improving the results of that organization, through the adequacy of the individual to perform a job, training, enhancement of human relationship between employers and their subordinates to increase productivity, promotions and career progressions determined for human potentials among other objectives. David (1985) ${ }^{[2]}$ looks at connections between the police and Hispanics in Texas. In particular, information were gathered on Hispanic assessments of police execution, desires for police execution, and generally speaking fulfillment with the police. Huge discoveries show that any type of contact with the police seemed to bring down the rating of police execution. This has all the earmarks of being a result of the communication between high open desires and subjectively helpless police execution. Thus, exploitation brought down the assessment of nearby police, the region sheriff, and the Department of Public Safety. Hispanics additionally saw that officials have an "awful demeanor," that the police need to watch and examine more, that reaction time ought to be improved, and that there should be less oppression Hispanics. Stroshine (1999) ${ }^{[3]}$ said the motivation behind the current examination is two-fold. To start with, utilizing information acquired from an example of wrong doing casualties this investigation observationally surveys the impact that cop race has on assessments of the police. 
Second, this investigation gives a more noteworthy determination of the impact that assumptions about police execution have on assessments of the police. ANOVA and Ordered Probit examinations demonstrate that cop race doesn't impact casualty assessments of police execution. Nonetheless, desires do essentially impact assessments of the police and moreover, desires for police execution vary across racial lines. Potential clarifications for these discoveries and bearings for future examination are advertised. Tengpongsthorn (2017) ${ }^{[4]}$ studied factors related to the effectiveness of the work of police officers in the Thai Metropolitan Police Office. Both quantitative and qualitative research using questionnaires and in-depth interviews as research tools have been carried out. The statistics used for the data analysis included the frequency, percentage, mean, standard deviation and Pearson correlation. Result reveals that motivating factors and hygiene factors have had positive relationships with job performance efficiency. Metropolitan police officers in all divisions deeply believed that sufficient equipment was a factor that facilitated an increase in work effectiveness, while the imbalance in personnel and the scarcity of sophisticated tech were factors that hindered work performance. According to Magalhaes et al. (1977) ${ }^{[5]}$ stated that "Performance evaluation is a systematization of the performance of the individual who occupies the function based on objective analysis of the behavior of man". The performance evaluation in the public sector like the police the objective of this research has a particular significance; because of its public character of course its performance has visibility to the ordinary citizen, who observes systematically what the police do. Capece $(2012)^{[6]}$ focuses on the socio-political advancement of the Police Force in the Republic of Mozambique. It examines the scenarios and organization characteristics that underlie the motivation and career development of its officers. He asserted that the performance of police officers can only be seen as sufficient and highly skilled through a free and accountable system. The data collection method included anonymous questionnaires and the use of semi-structured interviews between police officers, police commanders and managers of human resources. The result show that the vast majority of respondents did not understand the value of the performance assessment because the results are not legally applied in Mozambique, in particular the EGFAE and the police statute. Rosenbaum (2002) ${ }^{[7]}$ in his book, discussed very fundamental issue on crime prevention and detection. His work is in depth on the role of police in the prevention of crime, but failed to address to the minute detail of issue of enforcement of law. Also his work, though relevant for this research, it's not in tune with contemporary issue as they obtain in Nigeria. As we strengthen the capacity of police organization to response to public safety issue. Ericson et al. (1981) ${ }^{[9]}$ indicates that there is a symbiotic relationship between the police and the society involved in a mutually beneficial partnership between the government and the police; the police need the society to provide them with knowledge because the police have a strong interest in keeping a good public image.

The main significance of this study is that it will help improve the primary function and purpose of police as an institution for social justice, and as an agent of society for the general good of all. Inform the public property about the function as well, so that people can evaluate their performance. Furthermore this research may serve as a basis for further research on activities of the police most especially the relationship between the powers or other organization like the courts the prison and the traditional institution. The aim of this project research is to evaluate the performance of police in yelwa police division.

\section{Research Design}

For the research to get accurate data, the research work is design to find out the rate of awareness of police performance. This research design is carry out using chisquare and percentage as a tool which is been use to enhance the evaluation of police performance in yelwa police division.

Questionnaire was used for data collection. Therefore it's a (primary data). In assessing the objective in achieving the research goal as written information consent was obtained from each participant and anonymity of participant was maintained through the study. The questionnaire consisted of questions to assess the awareness of police performance within yelwa.

Chi-square is a measure of discrepancy between the observed and the expected frequency was employed for the study.

\section{Assumption in use of chi-square}

a. The data are obtained from random samples

b. The sample data of the frequency count consist of independent observation

c. The expected value in each cell must be five or more

Table 1: Data Presentation and Analysis Regression

\begin{tabular}{|c|c|c|}
\hline Enumeration Areas & Frequency & Percentage \\
\hline EA1 Yelwa tudu & 25 & $27.17 \%$ \\
\hline EA2 Yelwa Makaranta & 23 & $25 \%$ \\
\hline EA3 Yelwa Kagadama & 19 & $20.65 \%$ \\
\hline EA4 Yelwa Tsakani & 25 & $27.17 \%$ \\
\hline Total & 92 & $99.99 \%$ \\
\hline
\end{tabular}

The questionnaires were distributed based on the number of sample in each enumeration area as noted, Yelwa tudu has 25 respondent representing $27.17 \%$, Yelwa makaranta has 23 respondent representing 25\%, Yelwa kagadama has 19 respondent representing 20.65\%, Yelwa tsakani has 25 respondent representing $27.17 \%$, The table shows that Yelwa tudu and Yelwa tsakani has all the respondent that were been selected.

Table 2: Showing the educational qualification of the respondent

\begin{tabular}{|c|c|c|c|c|c|c|}
\hline \multicolumn{2}{|c|}{} & Frequency & Percent & Cumulative Frequency & Valid Percent & Cumulative Percent \\
\hline \multirow{4}{*}{ Valid } & Primary & 1 & 1.0 & 1 & 1.1 & 1.1 \\
\cline { 2 - 7 } & Secondary & 15 & 15.0 & 16 & 16.3 & 17.4 \\
\cline { 2 - 7 } & ND/NCE & 46 & 46.0 & 62 & 50.0 & 67.4 \\
\cline { 2 - 7 } & HND/BSC & 24 & 24.0 & 86 & 26.1 & 93.5 \\
\cline { 2 - 7 } & MSc. & 6 & 6.0 & 92 & 6.5 & 100.0 \\
\hline Missing & System & 8 & 8.0 & 100 & & \\
\hline \multicolumn{2}{|c|}{ Total } & 100 & 100.0 & & 100.0 & \\
\hline
\end{tabular}


From the table above, it shows that 1 representing $1.0 \%$ of the respondent are primary, 15 representing $15.0 \%$ of the respondent are secondary, 46 representing $46.0 \%$ of the respondent are ND/NCE, 24 representing $24.0 \%$ of the respondent are HND/BSC Holder, 6 representing $6.0 \%$ of the respondent are MSc. holder. These indicate that the majority of the respondents are ND/NCE.

Table 3: Does police use authority fairly efficiently and effectively

\begin{tabular}{|c|c|c|c|}
\hline Gender & Yes & No & Total \\
\hline Male & 30 & 26 & 56 \\
\hline Female & 16 & 20 & 36 \\
\hline Total & 46 & 46 & 92 \\
\hline
\end{tabular}

\section{Test of hypothesis}

Ho: The efficient and effective use of police authority is independent of gender.

H1: The efficient and effective use of police authority is dependent of gender.

\section{Level of significant}

$\alpha=0.05$ at (c-1), (r-1) degree of freedom

Critical region reject $\mathbf{H}_{\mathbf{0}}$ if $\chi^{2} \mathrm{Cal}>\chi^{2} \mathrm{Tab}$

$\chi_{\alpha}^{2}=\chi^{2} \alpha,(\mathrm{c}-1),(\mathrm{r}-1)=\chi^{2} 0.05,(2-1),(2-1)=\chi^{2} 0.05,1=$ 3.841

$E_{i j}=\frac{R * C}{T}$

$E_{11}=28, E_{12}=28, E_{13}=18, E_{22}=18$

$\chi^{2}=0.73$

Table 4: Does the present of police post within your community reduce the rate of crime

\begin{tabular}{|c|c|c|c|}
\hline Gender & Yes & No & Total \\
\hline Male & 15 & 40 & 55 \\
\hline Female & 27 & 10 & 37 \\
\hline Total & 42 & 50 & 92 \\
\hline
\end{tabular}

\section{Test of hypothesis}

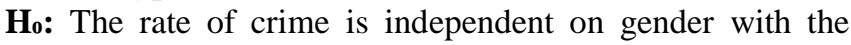
presence of police post

H1: The rate of crime is dependent on gender with the presence of police post

$\alpha=0.05$ at (c-1), (r-1) degree of freedom

Critical region reject $\mathbf{H}_{0}$ if $\chi^{2} \mathrm{Cal}>\chi^{2} \mathrm{Tab}$

$\chi_{\alpha}^{2}=\chi^{2} \alpha,(\mathrm{c}-1),(\mathrm{r}-1)=\chi^{2} 0.05,(2-1),(2-1)=\chi^{2} 0.05,1=$ 3.841

$E_{i j}=\frac{R * C}{T}$

$\chi^{2}=18.7$

Conclusion: Since $\chi^{2} \mathrm{Cal}>\chi^{2} \mathrm{Tab}$ we therefore reject $\mathbf{H}_{\mathbf{0}}$ and conclude that the present of police post within the community reduce the rate crime is independent of gender.

\section{Conclusion}

To some extent yelwa police division are fulfilling public expectation and the resident enjoyed a wide range of services from Yelwa Police Division. The research stated the important of awareness of police performance in yelwa police division and the role of police performance in yelwa. is to let people have the knowledge about the work of police and how to access their performance. The analysis was done in two part based on the statistical tools employed. The first part of the analysis was limited to the sample percentage of the respondent to see how people will rate police. Individual variable of the respondent are; age, gender, marital status, work status, educational attainment. The survey data for the performance measures are presented in appendix. Secondly using chi-square to access whether there are significant different or not in respondent rating, for each individual variable and the performance measures are crime prevention, handling offenders, and authority.

\section{Appendix}

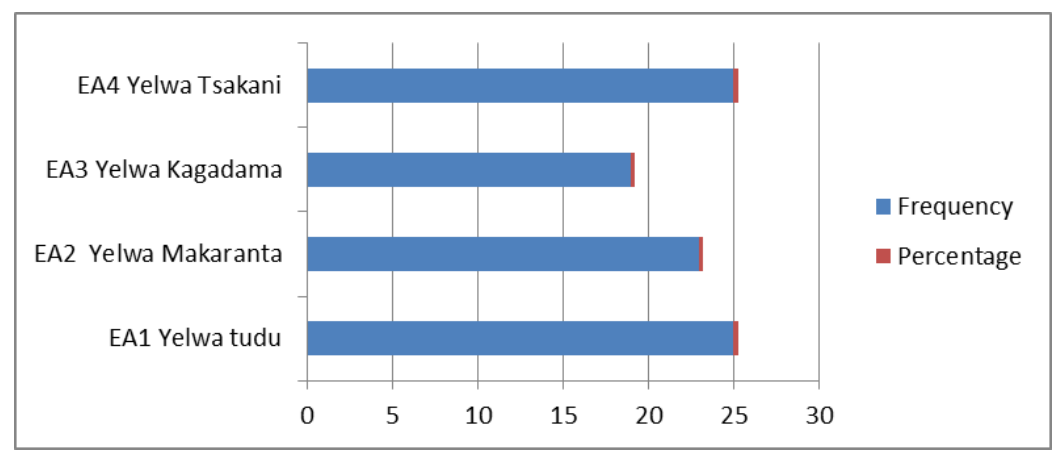

Fig 1: A bar chart of the Enumeration Area

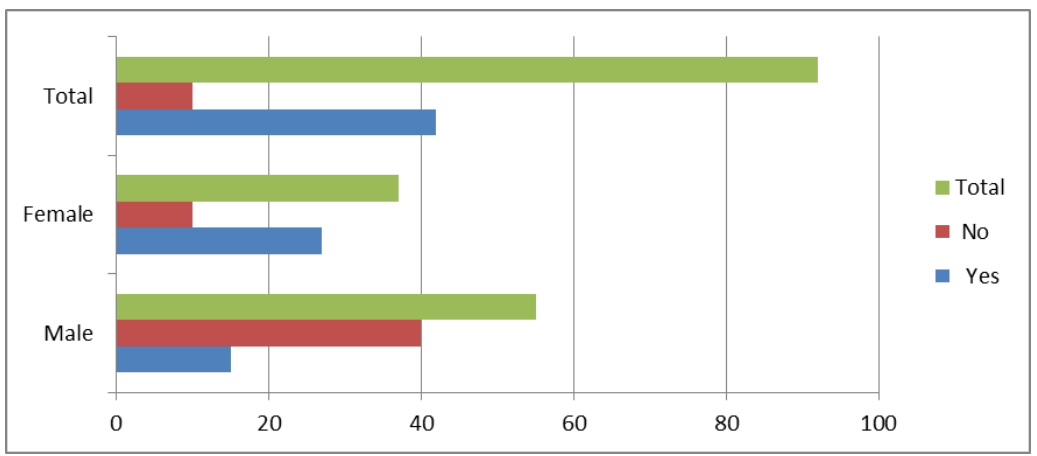

Fig 2: A bar chart of Present of police post in the community 


\section{Recommendations}

Since residents have no confident in police, there is need to educate general public on the role and power of police and the significance of public cooperation with police in order to promote an overall individual and national security. There should be a new public system, highly trained, wellmotivated to improve police and public friendliness.

\section{Reference}

1. Chiavenato, Idalberto. Comportamento organizacional: a dinâmica do sucesso das organizações. Editora Manole, 2005.

2. Carter, David L. "Hispanic perception of police performance: An empirical assessment." Journal of Criminal Justice. 1985; 13(6):487-500.

3. Chandek, Meghan Stroshine. "Race, expectations and evaluations of police performance." Policing: An International Journal of Police Strategies \& Management. Policing: An International Journal. 1999; 22(4):675-695.

4. Tengpongsthorn, Wuthichai. "Factors affecting the effectiveness of police performance in Metropolitan Police Bureau." Kasetsart Journal of Social Sciences. 2017; 38(1):39-44.

5. Magalhaes Gomes MP, Da Rocha Bastos L, Nobre Scheeffer R, Michael WB. Validation of the Teacher's Assessment of Students' Aptitudes FormTasaf. Educational and Psychological Measurement. 1977; 37(2):471-479.

6. Capece MC. Performance Evaluation, Motivation and Career Development in the Police Force of the Republic of Mozambique, (2006-2011).

7. Rosenbaum, Dennis P. "Evaluating multi-agency anticrime partnerships: Theory, design, and measurement issues." Crime prevention studies. 2002; 14:171-225.

8. Deakin, Nicholas, and Kieron Walsh. "The enabling state: the role of markets and contracts. "Public administration. 1996; 74(1):33-47.

9. Ericson, Richard V. Making crime: A study of detective work. Toronto: Butterworths, 1981. 